\title{
Selective Removal of Perfluorooctanoic Acid Using Molecularly Imprinted Polymer-Modified $\mathrm{TiO}_{2}$ Nanotube Arrays
}

\author{
Yunbo Wu, ${ }^{1,2}$ Yi Li, ${ }^{1}$ Aijun Tian, ${ }^{2}$ Kai Mao, ${ }^{2}$ and Jian Liu ${ }^{2}$ \\ ${ }^{1}$ Key Laboratory of Integrated Regulation and Resource Development of Shallow Lakes, Ministry of Education, College of Environment, \\ Hohai University, Xikang Road No. 1, Nanjing 210098, China \\ ${ }^{2}$ Jiangsu Province Key Laboratory of Environmental Engineering, Jiangsu Provincial Academy of Environmental Science, \\ Jiangdongbei Road No. 1, Nanjing 210036 China
}

Correspondence should be addressed to Yi Li; envly@hhu.edu.cn

Received 11 November 2015; Revised 21 January 2016; Accepted 26 January 2016

Academic Editor: Meenakshisundaram Swaminathan

Copyright (C) 2016 Yunbo Wu et al. This is an open access article distributed under the Creative Commons Attribution License, which permits unrestricted use, distribution, and reproduction in any medium, provided the original work is properly cited.

Perfluorinated chemicals have attracted worldwide concern owing to their wide occurrence and resistance to most conventional treatment processes. In this work, a novel photocatalyst was fabricated by modifying $\mathrm{TiO}_{2}$ nanotube arrays with molecularly imprinted polymers. The molecularly imprinted polymer-modified $\mathrm{TiO}_{2}$ nanotubes $\left(\mathrm{MIP}-\mathrm{TiO}_{2} \mathrm{NTs}\right)$ were characterized and tested for the selective removal of perfluorooctanoic acid (PFOA) from water. The amount of PFOA adsorbed by the $\mathrm{MIP}^{-T i O} \mathrm{NT}_{2}$ was as high as $0.8125 \mu \mathrm{g} / \mathrm{cm}^{2}$. PFOA decomposition and defluorination by the $\mathrm{MIP}-\mathrm{TiO}_{2}$ NTs reached $84 \%$ and $30.2 \%$ after $8 \mathrm{~h}$ reaction, respectively. The Freundlich model and pseudo-first-order kinetics were used to describe the observed adsorption and decomposition of PFOA, respectively. Compared with $\mathrm{TiO}_{2} \mathrm{NTs}$ and nonmolecularly imprinted polymer-modified $\mathrm{TiO}_{2} \mathrm{NTs}$, the MIP-TiO ${ }_{2}$ NTs exhibited not only a higher PFOA degradation rate but also enhanced selectivity for target chemicals. The $\mathrm{MIP}^{-T i O}{ }_{2}$ NTs could also selectively and rapidly remove PFOA from secondary effluent, exhibiting a decomposition of $81.1 \%$, almost as high as that observed in pure water. Investigation of the effects of scavengers on the photocatalytic reaction indicated that photogenerated holes were the main oxidant for PFOA decomposition, and the PFOA degradation mechanism and pathway were proposed.

\section{Introduction}

Perfluorinated chemicals $\left(\mathrm{C}_{n} \mathrm{~F}_{2 n+1} \mathrm{COOH}, \mathrm{PFCs}\right)$ are a class of anthropogenic organic compounds that have a wide range of applications, including in textiles, stain repellents, corrosion inhibitors, surfactants, and firefighting [1]. Owing to the high binding energy of C-F, PFCs have high chemical stability. This property makes PFCs persistent and bioaccumulative and has resulted in them becoming ubiquitously distributed in aquatic environments [1, 2]. Some PFCs, especially perfluorooctanoic acid (PFOA) and perfluorooctane sulfonate (PFOS), are commonly detected in surface water, sediments, and wastewater treatment plants (WWTPs) [3-5]. The evidence shows that these PFCs pose a potential risk to human health and aquatic organisms. For these reasons, the PFCs have had fixed strict limitations on the environmental surfactants concentration by some regulatory organizations and national governments [6].
Recently, much attention has been focused on eliminating PFCs from the environment using effective techniques under different conditions. Methods such as adsorption and advanced oxidation processes have been developed to remove PFCs from water $[2,7,8]$. Among these, adsorption is considered as suitable technology for PFCs from water or wastewater, such as activated carbon and molecularly imprinted polymers; the efficient adsorbents have high and selective adsorption for PFCs [2]. $\mathrm{TiO}_{2}$ photocatalysis is shown to be an effective process without harmful byproducts due to its capability to remove a wide range of pollutants and is coupled with other advantages in terms of high photochemical stability, being environmentally friendly, and low cost. It has previously been reported that $\mathrm{TiO}_{2}$ and modified $\mathrm{TiO}_{2}$ catalyst-mediated heterogeneous photocatalysis can be applied to PFC removal, with a considerable amount of the pollutant being degraded [8-12]. 
Adsorption throughout the degradation is a critical process that controls the reaction rate. However, in aquatic environments, especially in wastewater, there are many compounds and colloids that compete with PFCs and thus decrease the adsorption capacity of the adsorbent. Therefore, the development of affinity media that selectively removes PFCs from water and wastewater is of significant interest. Some researchers have reported that $\mathrm{TiO}_{2}$ alone displays low degradation capacity for organic compounds $[9,13]$. Many studies seek to hybridize $\mathrm{TiO}_{2}$ with selective adsorbents leveraging the advantages of both materials.

Molecular imprinting is a useful technique for preparing polymeric materials as specific molecular recognition receptors [14-16]. Molecularly imprinted polymers (MIPs) are prepared by polymerizing in the presence of cross-linkers and the polymerizable complexes formed from template species and monomers, which results in binding sites complementary to the template molecule. Du et al. reviewed methods for the preparation of MIPs with high selectivity and their adsorption behavior for PFCs (mainly PFOA and PFOS) [2]. Takayose et al. tried to synthesize a polymeric sorbent selective for PFOA using different monomers and crosslinkers and suggested that the MIP recognized PFOA via hydrogen bonding and fluorine-fluorine interactions [14]. Tran et al. developed a photoelectrochemical sensor fabricated by surface modification of $\mathrm{TiO}_{2}$ nanotube arrays with MIP. They reported that the as-prepared sensor was highly sensitive to PFOS and exhibited outstanding selectivity [16]. The results of the abovementioned studies show that MIP adsorption is an effective method for the selective removal of targeted PFCs from water.

However, most of the existing studies have merely focused on the development and adsorption mechanism of adsorbents for PFCs. So far, there have been no reports regarding the selective removal of PFCs using a technology that combines MIP adsorption and $\mathrm{TiO}_{2}$ photocatalysis. However, it has previously been reported that surface fluorination of the catalyst $\left(\mathrm{P} 25 \mathrm{TiO}_{2}\right)$ induced by fluoride ions released during the photodegradation of PFOA results in catalyst deactivation $[6,8]$. Additionally, the studies focused on photodegradation of PFCs were mostly carried out in deionized water, rather than real wastewater or WWTP secondary effluent, and some ions and other organics were shown to have significant effects on the photocatalytic degradation efficiency.

In the present paper, a new MIP-modified $\mathrm{TiO}_{2}$ nanotube $\left(\mathrm{MIP}-\mathrm{TiO}_{2} \mathrm{NT}\right)$ photocatalyst was developed to achieve selective removal of PFCs. The characteristics, sorption behaviors, and photocatalytic activity of the MIP-TiO 2 NTs were studied in detail. The proposed removal mechanism and possible surface fluorination during the photocatalysis process were investigated. The photocatalytic decomposition of PFCs from real secondary effluent using the MIP-TiO ${ }_{2}$ NTs was also evaluated.

\section{Materials and Methods}

2.1. Reagents. Titanium sheets $(99.60 \%, 0.06 \mathrm{~mm}$ thick) were purchased from Haiji Ltd. for Titanium \& Nickel, China. Perfluorooctanoic acid (PFOA), perfluorooctane sulfonate
(PFOS, potassium salt), acrylamide, 2,4-Dichlorophenoxyacetic acid (2,4-D), and perfluoroheptanoic acid (PFHA) were obtained from Sigma-Aldrich. 2,2' -Azobis (2-methylpropionitrile) (AIBN), ethylene glycol dimethacrylate (EGDMA), 3-methacryloxypropyl trimethoxysilane (MPTS), and 3-aminopropyltriethoxylsilane (APTS) were all purchased from Sinopharm Chemical Reagent Co., Ltd., China. Analytical standards for chromatography analyses were purchased from Sigma-Aldrich.

2.2. Preparation of $M I P-T_{i} O_{2}$ TNs. First, the preparation of $\mathrm{TiO}_{2}$ NTs was carried out on titanium foils using a procedure based on those used in our previous studies [15, 17]. The anodization was performed in a cylindrical electrochemical reactor with a DC power supply, with the $\mathrm{Ti}$ foil as the anodic electrode and nickel sheet as the cathode. A constant potential of $20 \mathrm{~V}$ was applied to the foils in an electrolyte containing $0.083 \mathrm{M} \mathrm{H}_{2} \mathrm{C}_{2} \mathrm{O}_{4} \cdot 2 \mathrm{H}_{2} \mathrm{O}$ and $0.5 \mathrm{wt} \% \mathrm{NH}_{4} \mathrm{~F}$ with magnetic stirring at room temperature. After the anodization, the samples were rinsed with deionized water, air-dried, and thermally annealed at $500^{\circ} \mathrm{C}$ for $2 \mathrm{~h}$. Highly ordered and vertically aligned $\mathrm{TiO}_{2}$ NTs were obtained.

The as-synthesized $\mathrm{TiO}_{2}$ NTs were pretreated in $0.5 \mathrm{M} \mathrm{NaOH}$ solution for $30 \mathrm{~min}$ to hydrolyze the $\mathrm{TiO}_{2}$ surface to form $\mathrm{Ti}-\mathrm{OH}$ groups and then rinsed with deionized water and air-dried. The molecularly imprinted polymers were fabricated on the $\mathrm{TiO}_{2}$ NTs as follows [14-16]: the $\mathrm{TiO}_{2}$ NTs were immersed into anhydrous toluene solution containing $1 \%(\mathrm{v} / \mathrm{v})$ APTS and $1 \%(\mathrm{v} / \mathrm{v})$ MPTS. The mixture was then purged with nitrogen gas for $15 \mathrm{~min}$ and heated at $60^{\circ} \mathrm{C}$ for $4 \mathrm{~h}$. The resulting APTS- and MPS-modified $\mathrm{TiO}_{2}$ NTs were washed with toluene and acetonitrile, respectively, and dried in nitrogen gas. Next, $10 \mathrm{mM}$ of the template (PFOA) was added to a mixture containing $12 \mathrm{~mL}$ methanol/acetonitrile $(1 / 1, \mathrm{v} / \mathrm{v})$ solution, $0.2 \mathrm{M}$ functional monomer (acrylamide), 1.4 M cross-linker (EGDMA), and $40 \mathrm{mM}$ initiator agent (AIBN). The solution was mixed uniformly by sonication for $5 \mathrm{~min}$ and then was slowly dropped onto two sides of the $\mathrm{TiO}_{2}$ NT sample to obtain a uniform coating. The coated $\mathrm{TiO}_{2} \mathrm{NTs}$ were inserted into a columniform quartz tube, which was sealed and purged with nitrogen for $20 \mathrm{~min}$. Polymerization was then carried out under $352 \mathrm{~nm}$ UV light irradiation for $12 \mathrm{~h}$. The molecular template was removed by immersing the prepared samples in methanol/deionized water $(1 / 1, \mathrm{v} / \mathrm{v})$ until no molecular template was detected in the eluate.

Nonmolecularly imprinted polymer-modified $\mathrm{TiO}_{2} \mathrm{NTs}$ (NIP-TiO 2 NTs) were also fabricated as a reference using the same method but without the addition of the template. The $\mathrm{TiO}_{2}$ NTs surface modified with molecularly imprinted polymers was denoted as $\mathrm{MIP}^{-\mathrm{TiO}_{2}}$ NTs.

2.3. Characterization. The morphology of the $\mathrm{TiO}_{2} \mathrm{NTs}$ was characterized by field-emission scanning electron microscopy (FESEM; Hitachi S-4800). The crystal structure of the photocatalyst was identified by X-ray diffraction (XRD) using a Rigaku D/max-rA diffractometer with $\mathrm{Cu} \mathrm{Ka}$ radiation. The completion of the polymerization reaction in the preparation of the $\mathrm{MIP}-\mathrm{TiO}_{2}$ NTs was 


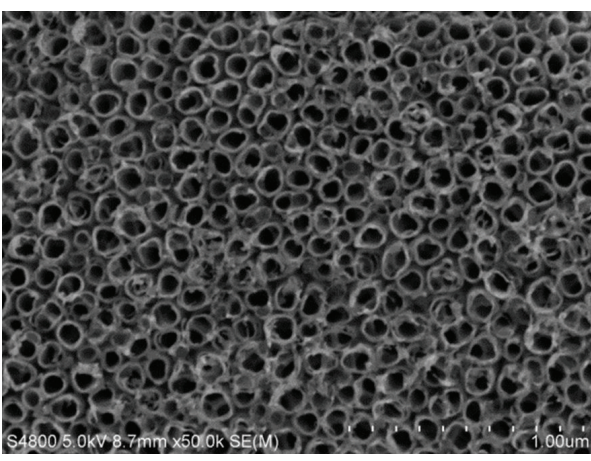

(a)

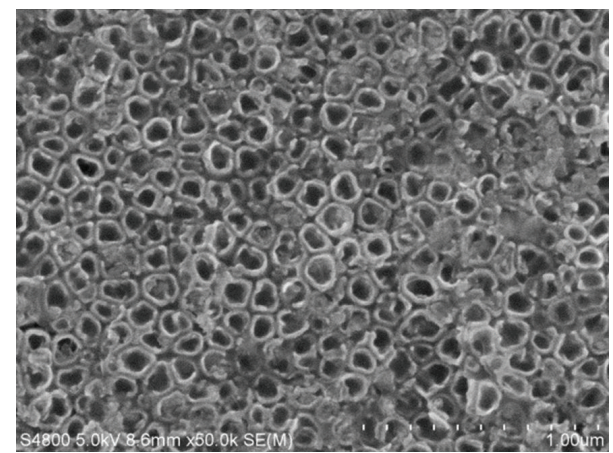

(b)

FIGURE 1: Surface-view FESEM images of (a) the unmodified $\mathrm{TiO}_{2} \mathrm{NTs}$ and (b) surface modified $\mathrm{TiO}_{2} \mathrm{NTs}_{\text {s }}$ by molecularly imprinted polymers (MIP-TiO 2 NTs).

confirmed by Fourier-transform infrared spectroscopy (FTIR; ThermoFisher Nicolet iS10). UV-vis diffuse reflectance spectra (DRS) were recorded on a Varian Cary 5000 spectrophotometer with an integrating sphere.

2.4. Batch Experiments. Adsorption of the chosen PFCs on the prepared materials was carried out in solution. In all batch adsorption experiments, four pieces of the prepared material (active area of $800 \mathrm{~cm}^{2} / \mathrm{L}$ ) were placed into $250 \mathrm{~mL}$ flasks containing $150 \mathrm{~mL}$ of PFOA/PFOS solution. All the experiments were carried out at $130 \mathrm{rpm}$ in a shaker bath for $36 \mathrm{~h}$ at $25^{\circ} \mathrm{C}$, and the sorption kinetics and sorption equilibrium were examined. Sorption isotherm experiments were conducted with initial PFOA concentrations ranging from 2 to $80 \mathrm{mg} / \mathrm{L}$ and an initial $\mathrm{pH}$ of 5 for $48 \mathrm{~h}$.

Similar to previous studies $[15,17]$, the photocatalytic experiments were conducted in a cylindrical quartz photocatalytic reactor. A quartz tube containing a low-pressure UV lamp (23 W, UV-C light at $254 \mathrm{~nm}$ ) was placed at the reactor center. The reaction solution contained an initial PFOA concentration of $30 \mathrm{mg} / \mathrm{L}$ in the presence/absence of four pieces of $\mathrm{MIP}_{-} \mathrm{TiO}_{2}$ TNs or NIP-TiO ${ }_{2}$ NTs. Prior to UV irradiation, the reaction mixture was stirred under dark conditions for $30 \mathrm{~min}$ to obtain adsorption-desorption equilibrium among the PFCs, $\mathrm{TiO}_{2}$, and oxygen. The temperature was controlled at $25 \pm 1^{\circ} \mathrm{C}$ using a circulating water bath. The initial $\mathrm{pH}$ value of the reaction solution was adjusted with $\mathrm{HNO}_{3}$ or $\mathrm{NaOH}$. Aliquots were taken from the system at desired time intervals and analyzed by HPLC.

To investigate the selectivity of the MIP-TiO 2 TNs, $150 \mathrm{~mL}$ of solution containing PFOA, PFOS, 2,4-D, or PFHA was added to the $250 \mathrm{~mL}$ reaction flask. The initial $\mathrm{pH}$ of the solution was adjusted to 5 .

2.5. Analytical Methods. The concentrations of PFOA, PFOS, and PFHA in the reaction solutions were measured with an e2695-HPLC equipped with a 432 conductivity detector and an XBridge C18 column $(4.6 \mathrm{~mm} \times 250 \mathrm{~mm})$ (Waters Technologies, USA). A mixture of methanol and $0.02 \mathrm{M}$ aqueous $\mathrm{NaH}_{2} \mathrm{PO}_{4}(75 / 25, \mathrm{v} / \mathrm{v})$ was used as the mobile phase, with a flow rate of $1.0 \mathrm{~mL} / \mathrm{min}$ at $40^{\circ} \mathrm{C}$. The concentration of $2,4-$ $\mathrm{D}$ was determined using the same HPLC but with a mobile phase consisting of 70\% methanol and 30\% phosphoric acid buffer at $\mathrm{pH}$ 2.3. The wavelength was established at $214 \mathrm{~nm}$ [18].

The total organic carbon (TOC) analysis was used to evaluate and to monitor the trend of the carbon content of the PFOA by photocatalysis of MIP-TiO 2 NTs. TOC analyses were performed with a TOC analysis system (Shimadzu ${ }^{\oplus}$ TOC 5000A) with a combustion/nondispersive infrared (NDIR) gas analysis method.

According to a previous study [13], the concentration of fluoride ions generated in the degradation samples was monitored with an ion chromatography system (Dionex ICS2000) equipped with a degasser, an autosampler, a guard column (IonPac AG11-HC), a separation column (IonPac AS11$\mathrm{HC})$, a column heater $\left(30^{\circ} \mathrm{C}\right)$, and a conductivity detector with a suppressor. The mobile phase was an aqueous solution of $\mathrm{KOH}(30 \mathrm{mmol} / \mathrm{L})$ with a flow rate of $1.0 \mathrm{~mL} / \mathrm{min}$. The suppressor current was set at $124 \mathrm{~mA}$.

\section{Results and Discussion}

3.1. Characterization of Prepared Materials. The surface morphology of the prepared $\mathrm{TiO}_{2}$ NTs and $\mathrm{MIP}-\mathrm{TiO}_{2}$ NTs is shown in Figure 1. In both cases, well-ordered and uniform $\mathrm{TiO}_{2}$ nanotubes were grown over the entire titanium substrate. The $\mathrm{TiO}_{2}$ NTs had an inner pore diameter ranging from 70 to $100 \mathrm{~nm}$ and wall thickness of approximately $14 \mathrm{~nm}$. After molecularly imprinted polymerization, the molecularly imprinted polymer was uniformly deposited onto the surface of the $\mathrm{TiO}_{2}$ NTs. The $\mathrm{TiO}_{2}$ NTs covered with a thin MIP layer still kept their open-top character and only decreased in average diameter to approximately $10 \mathrm{~nm}$, as shown in Figure 1(b). Figure 2 shows the XRD patterns of the unmodified $\mathrm{TiO}_{2} \mathrm{NTs}$ and $\mathrm{MIP}-\mathrm{TiO}_{2}$ NTs, which indicate that the $\mathrm{TiO}_{2}$ NTs were mainly anatase and rutile in phase.

The UV-vis spectra of the $\mathrm{TiO}_{2}$ NTs, NIP-TiO ${ }_{2}$ NTs, and $\mathrm{MIP}-\mathrm{TiO}_{2} \mathrm{NTs}$ are presented in Figure 3. Compared with that of the naked $\mathrm{TiO}_{2}$ NTs, it is clear that the absorption intensity of the NIP-TiO ${ }_{2}$ NTs and MIP-TiO 2 NTs was significantly increased in the UV and visible light range. The spectra of the latter two materials also showed a red shift, which was attributed to the imprinted polymer layer on the $\mathrm{TiO}_{2}$ surface. 


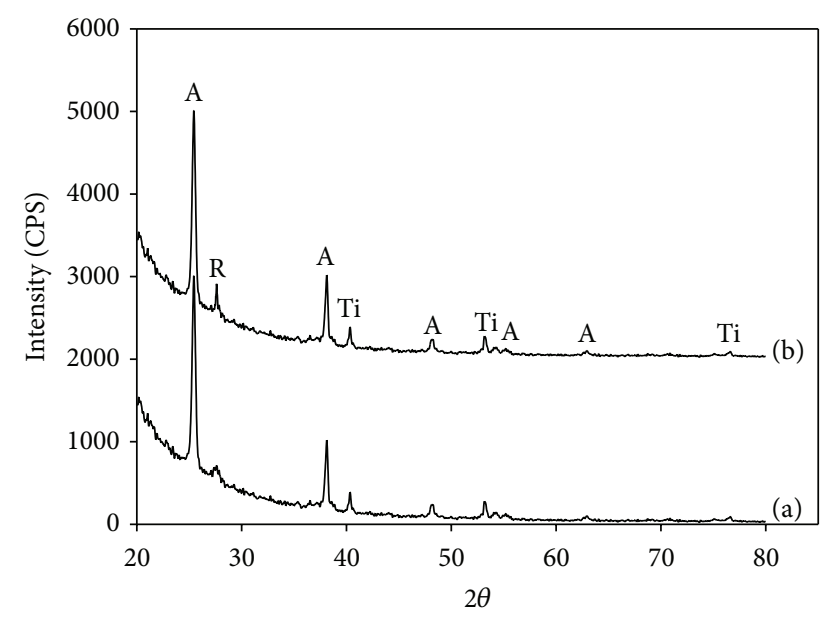

A: anatase

Ti: titanium

R: rutile

FIgURE 2: XRD patterns of (a) the unmodified $\mathrm{TiO}_{2}$ NTs and (b) $\mathrm{MIP}^{-T i O}{ }_{2}$ NTs.

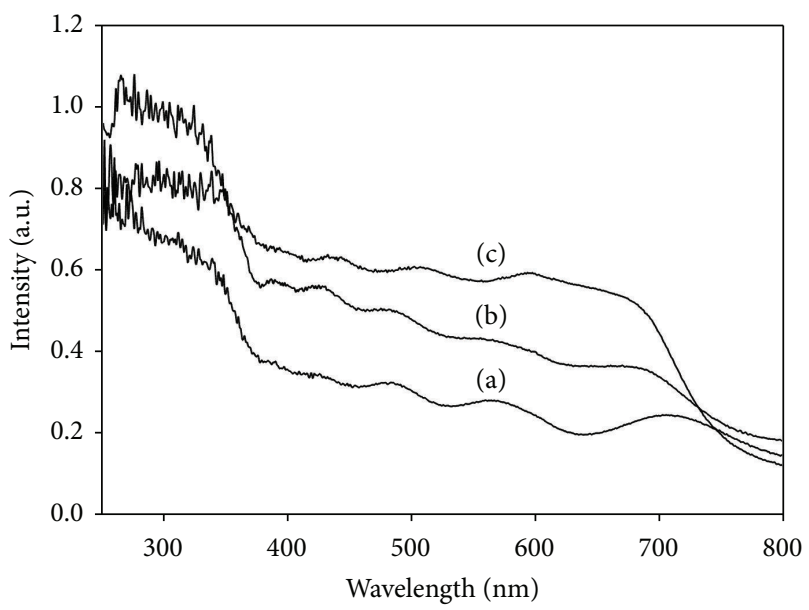

FIgURE 3: UV-vis spectra of (a) $\mathrm{TiO}_{2} \mathrm{NTs}$, (b) $\mathrm{NIP}^{-\mathrm{TiO}_{2}} \mathrm{NTs}$, and (c) $\mathrm{MIP}_{-\mathrm{TiO}}$ NTs.

Moreover, the absorption intensity of $\mathrm{MIP}^{-\mathrm{TiO}_{2}} \mathrm{NTs}$ was lower than that of NIP-TiO ${ }_{2}$ NTs at wavelengths between 250 and $350 \mathrm{~nm}$. This may be because the surface imprinted layer covered the active sites of $\mathrm{TiO}_{2}$.

The FT-IR is a highly sensitive method to characterize structure of molecular-imprinted $\mathrm{TiO}_{2}$ film. Figure 4 shows the FT-IR spectra of acrylamide, $\mathrm{TiO}_{2}$ NTs, NIP-TiO ${ }_{2} \mathrm{NTs}$, and $\mathrm{MIP}_{-} \mathrm{TiO}_{2}$ NTs. The unmodified $\mathrm{TiO}_{2}$ NTs showed no significant absorptions (curve (a)). After the surface modification of the $\mathrm{TiO}_{2} \mathrm{NTs}$, a N-H bending mode at around $1612 \mathrm{~cm}^{-1}, \mathrm{C}=\mathrm{O}$ amide stretching mode at around $1672 \mathrm{~cm}^{-1}$, $\mathrm{C}-\mathrm{N}$ stretching mode at around $1134 \mathrm{~cm}^{-1},=\mathrm{C}-\mathrm{H}$ and $=\mathrm{CH}_{2}$ out-of-plane bending modes at around $958 \mathrm{~cm}^{-1}$, and $\mathrm{N}-\mathrm{H}$ stretching mode at around $3360 \mathrm{~cm}^{-1}$ were observed (curve (b)), all of which were consistent with the characteristic peaks of the functional monomer acrylamide (curve (b)).

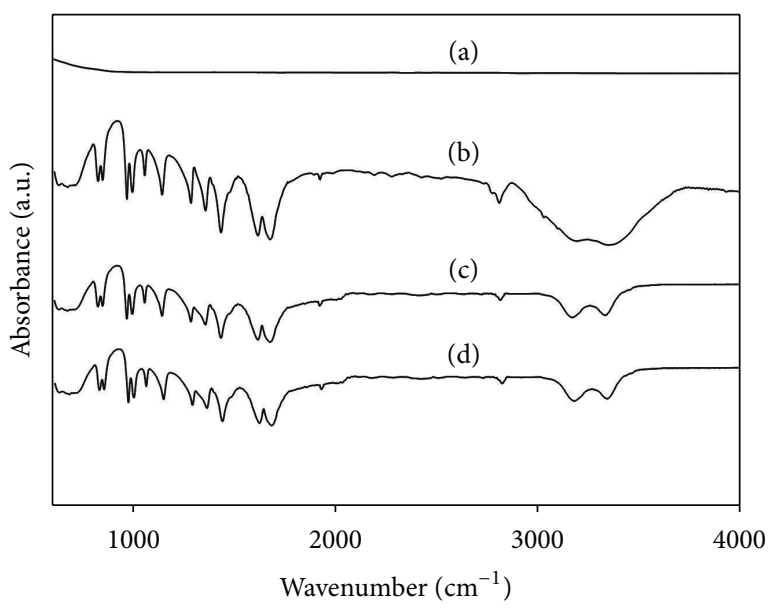

FIgURE 4: FT-IR spectra of (a) $\mathrm{TiO}_{2}$ NTs, (b) pure acrylamide, (c) MIP-TiO 2 NTs, and (d) NIP-TiO 2 NTs.

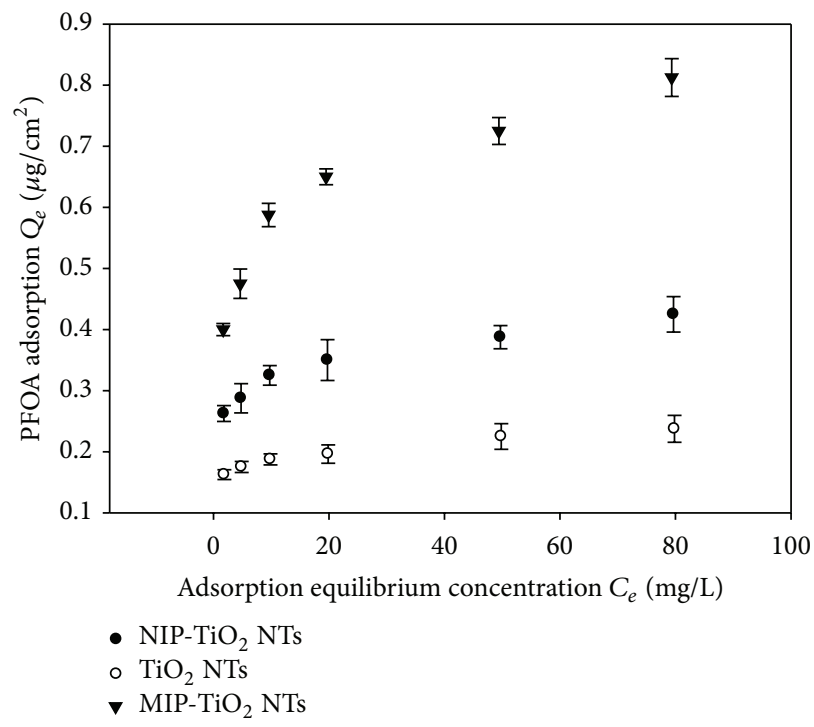

FIGURE 5: The adsorption capacity of different absorbents towards PFOA in aqueous solution.

Among the characteristic peaks of PFOA, signals in the range of $1300-1100 \mathrm{~cm}^{-1}$ are attributed to C-F stretching $[6,13]$. These characteristic peaks were not present in the spectra of the MIP- and NIP-TiO 2 NTs (curves (c) and (d)), which confirmed that PFOA was removed after the rinsing of the samples with $\mathrm{CH}_{3} \mathrm{OH}$ solution.

3.2. Adsorption Performance. The amount of PFOA sorption by the different adsorbents as a function of residual PFOA concentration in the test solution is presented in Figure 5. Percentage of PFOA adsorption for different adsorbents at various initial concentrations was given in Table 1. The amount bound to both the MIP and NIP-TiO ${ }_{2}$ NTs clearly increased as the PFOA concentration was increased. Moreover, the amount of PFOA adsorbed by the MIP-TiO 2 NTs was much greater than that by the NIP-TiO 2 NTs or $\mathrm{TiO}_{2} \mathrm{NTs}$, 
TABLE 1: Percentage of PFOA adsorption for different adsorbents at various initial concentrations (\%).

\begin{tabular}{|c|c|c|c|}
\hline Adsorbents & $20 \mathrm{mg} / \mathrm{L}$ & $50 \mathrm{mg} / \mathrm{L}$ & $80 \mathrm{mg} / \mathrm{L}$ \\
\hline $\mathrm{TiO}_{2} \mathrm{NTs}$ & 0.79 & 0.90 & 0.95 \\
\hline $\mathrm{NIP}^{-\mathrm{TiO}_{2}}$ NTs & 1.4 & 1.55 & 1.7 \\
\hline $\mathrm{MIP}^{-\mathrm{TiO}_{2}} \mathrm{NTs}$ & 2.6 & 2.9 & 3.25 \\
\hline
\end{tabular}

TABLE 2: Fitting parameters of Freundlich isotherms for PFOA sorption.

\begin{tabular}{lccc}
\hline Adsorbents & $1 / n$ & $K_{f}$ & $R^{2}$ \\
\hline $\mathrm{TiO}_{2} \mathrm{NTs}$ & 0.1017 & 0.150 & 0.9823 \\
$\mathrm{NIP}_{-\mathrm{TiO}}$ NTs & 0.1257 & 0.241 & 0.9923 \\
$\mathrm{MIP}-\mathrm{TiO}_{2} \mathrm{NTs}$ & 0.1811 & 0.370 & 0.9837 \\
\hline
\end{tabular}

revealing that the imprinting polymerization process had a significant influence on PFOA adsorption. The amount of PFOA adsorbed on the MIP-TiO 2 NTs reached $0.8125 \mu \mathrm{g} / \mathrm{cm}^{2}$ when the initial concentration of PFOA was $80 \mathrm{mg} / \mathrm{L}$.

Based on the observed adsorption performance of the $\mathrm{MIP}-\mathrm{TiO}_{2}$ NTs in aqueous solution, the Freundlich model was used to describe the adsorption isotherm:

$$
Q_{e}=K_{f} C_{e}^{1 / n}
$$

where $Q_{e}$ is the amount of PFOA adsorbed per unit active surface area of the MIP $\left(\mathrm{mg} / \mathrm{cm}^{2}\right) ; K_{f}$ is the adsorption equilibrium constant representative of the adsorption capacity; $1 / n$ is a constant indicative of the adsorption intensity; and $C_{e}$ is the equilibrium concentration $(\mathrm{mg} / \mathrm{L}) . R^{2}$ is square of correlation coefficient. The calculated adsorption coefficients of the adsorption isotherms are listed in Table 2. The coefficients $1 / n$ and $K_{f}$ of the MIP-TiO 2 NTs were higher than those of the other samples. These results indicated that the observed difference in adsorption capacity and intensity should be attributed to the footprint cavities existing in the imprinted polymers. The enhanced adsorption of PFOA on the absorbents was caused by the presence of special binding sites $[14,16,19]$. Only the template molecules could be bound in these sites, which required not only specific functional groups $\left(-\mathrm{NH}_{2}\right)$ but also matching target molecule size. The acrylamide monomer and PFOA target molecules polymerized together. The target molecules were removed and left a special polymer with voids of particular shape and size [16]. However, some functional monomers that did not form complexes remained on the surface of the polymer after polymerization. These monomers and remaining crosslinker provided the possibility of nonspecific adsorption via hydrogen bonding [15]. Hence, the NIP-TiO 2 NTs exhibited enhanced absorption capacity compared with that of the $\mathrm{TiO}_{2}$ NTs. The present imprinted polymerization process is therefore thought to result in high recognition of the target pollutant and its removal.

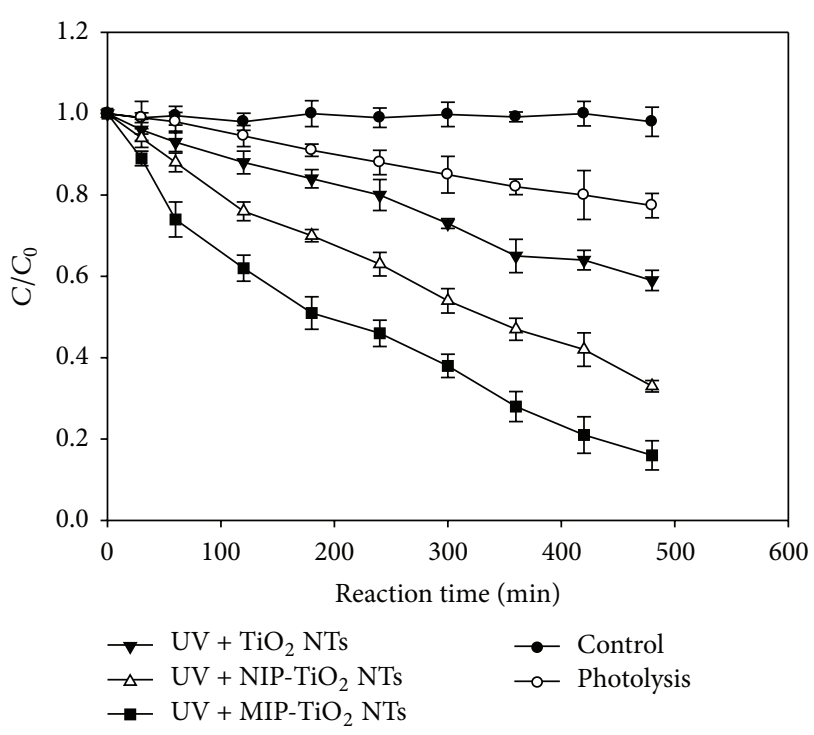

Figure 6: Comparison of PFOA degradation kinetics towards UV photolysis, $\mathrm{TiO}_{2}$ NTs, NIP-TiO 2 NTs, and $\mathrm{MIP}_{2} \mathrm{TiO}_{2}$ NTs. Initial solution concentration $C_{0}$ and $\mathrm{pH}$ are $30 \mathrm{mg} / \mathrm{L}$ and 5 , respectively.

\subsection{Photocatalytic Degradation of PFOA}

3.3.1. Degradation Kinetics. The photocatalytic activity of the MIP-TiO 2 NTs, NIP-TiO 2 NTs, and $\mathrm{TiO}_{2}$ NTs was evaluated in aqueous PFOA solution. Figure 6 shows the decomposition of PFOA by the catalysts under UV irradiation. No significant changes in PFOA concentration were observed during control tests (without UV irradiation). Moreover, the maximum amount of PFOA adsorbed during adsorption equilibrium experiments was just $0.52 \mathrm{mg} / \mathrm{L}$ for an initial concentration of $30 \mathrm{mg} / \mathrm{L}$. It is therefore obvious that PFOA decomposition was mainly attributed to photolysis or photocatalysis. Direct photolysis caused 22.6\% PFOA degradation after $8 \mathrm{~h}$ UV irradiation. PFOA can be efficiently photodecomposed under light of 220-460 nm wavelengths $[12,20]$. The degradation of PFOA in the presence of $\mathrm{TiO}_{2}$ NTs or NIP-TiO 2 NTs ( $41 \%$ and $67 \%$, resp.) was more efficient than that of the direct photolysis. In the presence of $\mathrm{MIP}-\mathrm{TiO}_{2}$ NTs, the decomposition ratio of PFOA dramatically increased to over $84 \%$ after $8 \mathrm{~h}$ irradiation. The photocatalytic reaction kinetics followed the Langmuir-Hinshelwood model [6]:

$$
r=\frac{d C}{d t}=K_{\mathrm{app}} C
$$

The reaction mechanism can be approximated to a pseudo-first-order kinetic reaction. In (2), $r$ is the reaction rate, $C$ is the PFOA concentration of the solution, $t$ is the time, and $K_{\text {app }}$ is the first-order rate constant. PFOA decomposition followed pseudo-first-order kinetics with rate constants of $0.0006,0.0011,0.0022$, and $0.0036 \mathrm{~min}^{-1}$ for direct photolysis (Table 3 ), and degradation in the presence of $\mathrm{TiO}_{2} \mathrm{NTs}$, NIP-TiO 2 NTs, and MIP-TiO 2 NTs, respectively. Thus, it is clear that the MIP-TiO 2 NTs showed the greatest photocatalytic activity for PFOA decomposition, with a higher decomposition rate than the other methods. 
TABLE 3: Kinetic data for direct photolysis and photocatalytic degradation of PFOA.

\begin{tabular}{|c|c|c|}
\hline Reaction condition & $K_{\text {app }}\left(\min ^{-1}\right)$ & $R^{2}$ \\
\hline Photolysis & 0.0006 & 0.998 \\
\hline $\mathrm{TiO}_{2} \mathrm{NTs}$ & 0.0011 & 0.9878 \\
\hline $\mathrm{NIP}^{-\mathrm{TiO}_{2}}$ NTs & 0.0022 & 0.9905 \\
\hline $\mathrm{MIP}^{-\mathrm{TiO}_{2}}$ NTs & 0.0036 & 0.9872 \\
\hline
\end{tabular}

The enhanced adsorptivity of the MIP layer increased the opportunity of contaminants coming into contact with the $\mathrm{TiO}_{2}$ material [21-23]. It is reported that the adsorption of contaminants on photocatalyst surfaces is a prerequisite for photodecomposition, because the degradation reaction occurs on the surface of a catalyst rather than in bulk solution [15]. Based on the above analysis of adsorption performance, the MIP layer on the $\mathrm{TiO}_{2}$ NTs surface provided special binding sites and hydrogen bonding for PFOA adsorption, which caused the MIP-TiO 2 NTs to exhibit outstanding adsorption capacity and photocatalytic activity towards the template compounds. Furthermore, negatively charged surface was formed after PFOA $\left(\mathrm{C}_{7} \mathrm{~F}_{15} \mathrm{COO}^{-}\right)$was adsorbed on the surface of the MIP-TiO ${ }_{2}$ NTs. When the titanium dioxide was excited under UV irradiation, electrostatic attraction between this negatively charged and the catalyst surface would have retarded charge recombination and promote surface reactions with valence band holes $\left(\mathrm{h}^{+}\right)$, which are advantageous in PFOA decomposition and defluorination $[9,24]$.

The amount of fluoride ions $\left(\mathrm{F}^{-}\right)$present in the reaction solutions was determined by IC. The changes in the concentration of PFOA and $\mathrm{F}^{-}$are shown in Figure 7. The defluorination ratios were calculated as follows:

$$
D_{f}=\frac{C_{\mathrm{F}^{-}}}{C_{0} \times 15} \times 100 \%,
$$

where $C_{\mathrm{F}}$ is concentration of fluoride ions $(\mu \mathrm{mol} / \mathrm{L}), C_{0}$ is the initial concentration of PFOA $(72.5 \mu \mathrm{mol} / \mathrm{L})$, and the factor of 15 corresponds to the number of fluorine atoms in one PFOA molecule. After $8 \mathrm{~h}$ irradiation, the defluorination of PFOA by direct photolysis, $\mathrm{TiO}_{2}$ NTs, NIP-TiO ${ }_{2}$ NTs, and MIP$\mathrm{TiO}_{2}$ NTs was $5.4 \%, 9.7 \%, 15.7 \%$, and $30.2 \%$, respectively. Figure 7(b) shows that the amount of $\mathrm{F}^{-}$that responded to the change of PFOA concentration gradually increased with irradiation time in the presence of $\mathrm{MIP}-\mathrm{TiO}_{2}$ NTs. The PFOA defluorination ratios were much smaller than the PFOA decomposition ratios. This implies that intermediate products formed during photocatalysis $[8,10,11]$. Figure $7(\mathrm{c})$ shows the trends of TOC that responded to the change of PFOA concentration in the presence of MIP-TiO ${ }_{2}$ NTs. As can be seen, almost $46 \%$ of TOC was removed. It is possible that the total $\mathrm{F}$ content of the aqueous reaction solutions consisted of four parts, that is, remaining PFOA, shorterchain PFCs, $\mathrm{F}^{-}$, and PFCs adsorbed on the catalyst surface $[11,13]$.

3.3.2. Selective Photocatalysis. To investigate the selectivity of the MIP-TiO 2 NTs, the photocatalytic activity of the material
TABLE 4: Apparent rate constant $K_{\text {app }}$ and selectivity $K_{s}$ for photocatalytic degradation in single-solute solution.

\begin{tabular}{lccc}
\hline Pollutant & $K_{\text {app }}\left(\mathrm{min}^{-1}\right)$ or $K_{s}$ & $\mathrm{MIP}^{-T i O} \mathrm{NTs}_{2}$ & $\mathrm{NIP}_{-} \mathrm{TiO}_{2} \mathrm{NTs}$ \\
\hline \multirow{2}{*}{ PFOA } & $K_{\text {app }}$ & 0.0044 & 0.0024 \\
& $K_{s}$ & - & 1.83 \\
\hline \multirow{2}{*}{ PFHA } & $K_{\text {app }}$ & 0.0032 & 0.0025 \\
& $K_{s}$ & - & 1.28 \\
\hline \multirow{2}{*}{ PFOS } & $K_{\text {app }}$ & 0.0024 & 0.0015 \\
& $K_{s}$ & - & 1.6 \\
\hline \multirow{2}{*}{$2,4-\mathrm{D}$} & $K_{\text {app }}$ & 0.0012 & 0.001 \\
& $K_{s}$ & - & 1.2 \\
\hline
\end{tabular}

$K_{s}$ is calculated as $K_{\mathrm{MIP}} / K_{\mathrm{NIP}}$. $K_{\mathrm{MIP}}$ and $K_{\mathrm{NIP}}$ represent pollutant degradation rate in the presence of $\mathrm{MIP}-\mathrm{TiO}_{2}$ NTs and NIP-TiO ${ }_{2} \mathrm{NTs}$, respectively.

for PFOA decomposition was compared with that observed for PFOS, PFHA, and 2,4-D decomposition in the presence of MIP-TiO 2 NTs or NIP-TiO 2 NTs. Although these pollutants all exhibit anionic property in aqueous solution, they have different molecular structures. All of the degradation experiments were carried out under the same conditions, and the pollutants were all the same concentration of $50 \mu \mathrm{mol} / \mathrm{L}$. The results are given in Table 4. As expected, the MIP-TiO ${ }_{2}$ NTs exhibited the highest degradation efficacy for PFOA among the pollutants and markedly enhanced photodegradation for all the target pollutants. The apparent rate constant $\left(K_{\text {app }}\right)$ for PFOA degradation and the selectivity $\left(K_{s}\right)$ in single-solute are also shown in Table 4. Comparison of the observed $K_{\text {app }}$ of the MIP and NIP-TiO ${ }_{2}$ NTs for the three pollutants suggests that the MIP is selective for PFOA but nonselective for the other pollutants. PFOS and PFOA are linear C8 compounds, while 2,4-D has a benzene ring in its molecular structure, which affected the recognition effect and resulted in low removal rates $[16,19]$. PFHA and PFOA have similar molecular structures with long-chain $-\mathrm{CF}_{2}$ and end carboxylic groups, so the PFHA removal rate was closer to that of PFOA. The higher rate constant $K_{\text {app }}$ observed for 2,4-D using the MIP- $\mathrm{TiO}_{2}$ may be attributed to its carboxylic groups similar to those of PFOA. Moreover, the results indicated that MIPmodified $\mathrm{TiO}_{2}$ might selectively remove a group of PFCs from water.

Competitive degradation experiments were carried out by measuring the concentration of the photocatalytic target PFOA $(50 \mu \mathrm{mol} / \mathrm{L})$ in the absence or presence of competitors $(25 \mu \mathrm{mol} / \mathrm{L})$. The results are shown in Figure 8 . Here, the PFOA removal rate is given to display the effects of the competitors on the photodegradation. When no competitive pollutant was added, the PFOA removal percentage was $89 \%$ in the presence of $\mathrm{MIP}^{-\mathrm{TiO}_{2}}$ NTs. The removal percentage was decreased to $65.8 \%, 74.3 \%$, and $83.7 \%$ when PFHA, PFOS, and 2,4-D were added as competitors, respectively. Obviously, the displacement of the competitors was dependent on their structure; the two competitive pollutants (PFHA and PFOS) with similar structure to that of the target (PFOA) significantly inhibited the photodegradation of the target $[16,21]$. In the presence of $\mathrm{NIP}^{-\mathrm{TiO}_{2}} \mathrm{NTs}$, the pollutants displayed competitive adsorption on the catalyst 


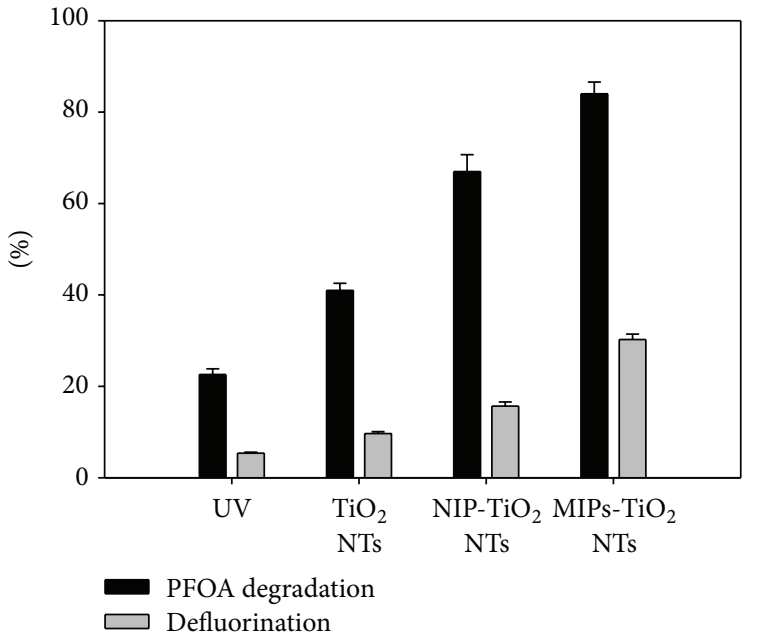

(a)

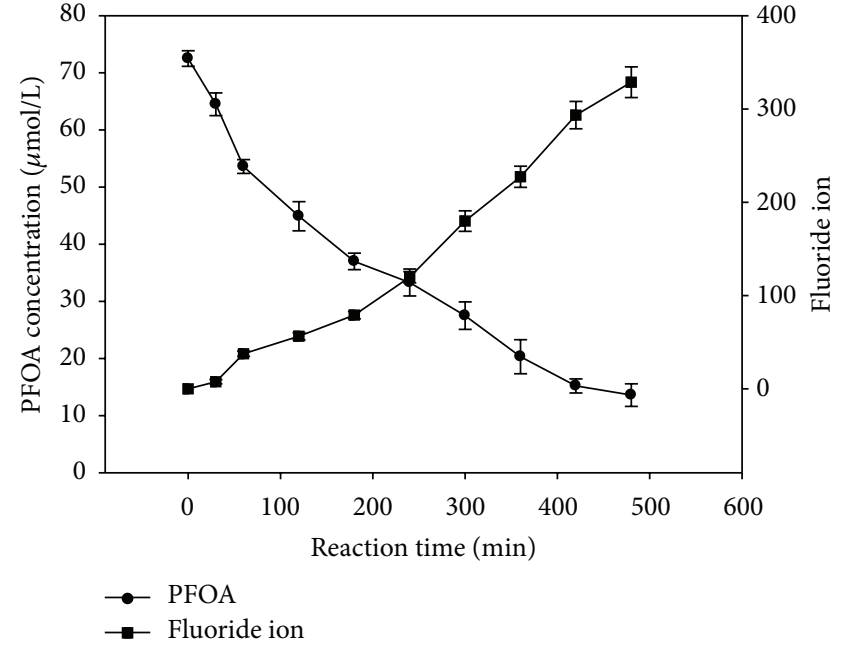

(b)

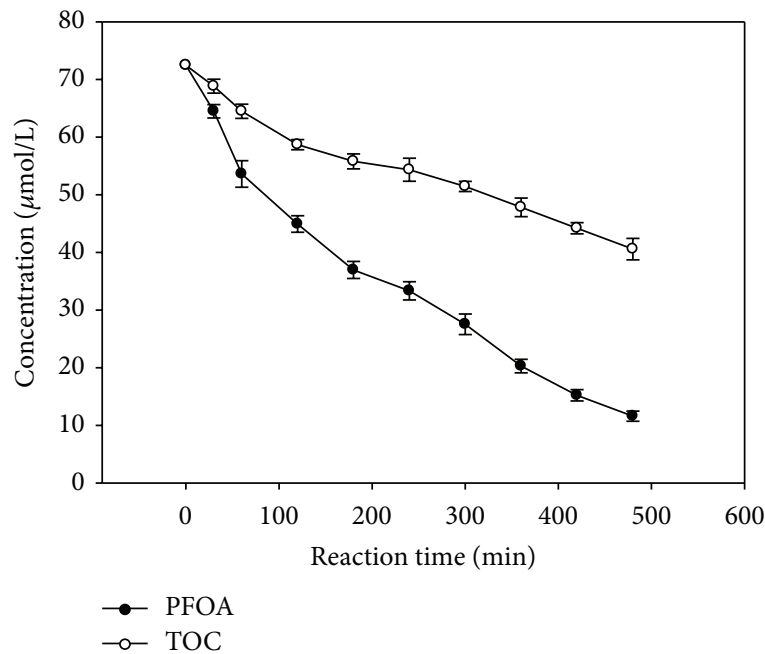

(c)

Figure 7: (a) PFOA degradation and defluorination towards UV photolysis, $\mathrm{TiO}_{2}$ NTs, NIP-TiO $\mathrm{NT}_{2}$, and $\mathrm{MIP}^{\mathrm{T}} \mathrm{TiO}{ }_{2}$ NTs under $8 \mathrm{~h}$ irradiation; (b) release of fluoride ion responded to the change of PFOA concentration in the presence of MIP-TiO 2 NTs; (c) trends of total organic carbon responded to the change of PFOA concentration in the presence of $\mathrm{MIP}^{-\mathrm{TiO}_{2}} \mathrm{NT}$. Initial concentrations of PFOA and TOC were $72.5 \mu \mathrm{mol} / \mathrm{L}(30 \mathrm{mg} / \mathrm{L})$.

surface and absorption of reactive oxygen species. Therefore, the above results demonstrate that MIP not only had high photocatalytic efficiency, but also possessed a strong ability to selectively photodegrade PFCs in mixed solutions.

3.4. Degradation in Secondary Effluent. In both WWTP secondary effluent and natural water, PFOA generally coexists with other chemical compounds, such as organic pollutants, natural organic matter, nitrate, and bicarbonate, which may reduce the PFOA decomposition efficiency by $\mathrm{TiO}_{2}$ photocatalysis $[13,25]$. To evaluate the feasibility of $\mathrm{MIP}^{2} \mathrm{TiO}_{2}$ NTs to decompose PFOA in real wastewater, we investigated the decomposition of PFOA added to secondary effluent taken from a municipal wastewater plant (in Suzhou, China), in which the anaerobic-anoxic-oxic process was used as a secondary treatment.
The secondary effluent contained a total organic content (TOC) of $10.2 \mathrm{mg} / \mathrm{L}$ and had a $\mathrm{pH}$ of 7.2. The $\mathrm{pH}$ of the reaction solution was adjusted to 5.0. The experiments of PFOA degradation in secondary effluent (SE) and pure water (PW) were carried out. Figure 9 shows the decomposition of PFOA by only UV and in the presence of the photocatalysts in both the secondary effluent (SE) and pure water (PE). After $8 \mathrm{~h}$ reaction in pure water, $22.6 \%, 67 \%$, and $84 \%$ of the PFOA were decomposed. Additionally, $18 \%, 50.2 \%$, and $81.1 \%$ were decomposed in the secondary effluent by UV, UV/NIP-TiO ${ }_{2}$ NTs, and UV/MIP-TiO ${ }_{2}$ NTs, respectively. It is evident that the degradation of PFOA was almost inhibited in secondary effluent.

Without any photocatalyst, PFOA decomposed more efficiently in pure water than in secondary effluent under UV light irradiation. Giri et al. found that water quality profoundly impacted PFOA photomineralization [26]. 


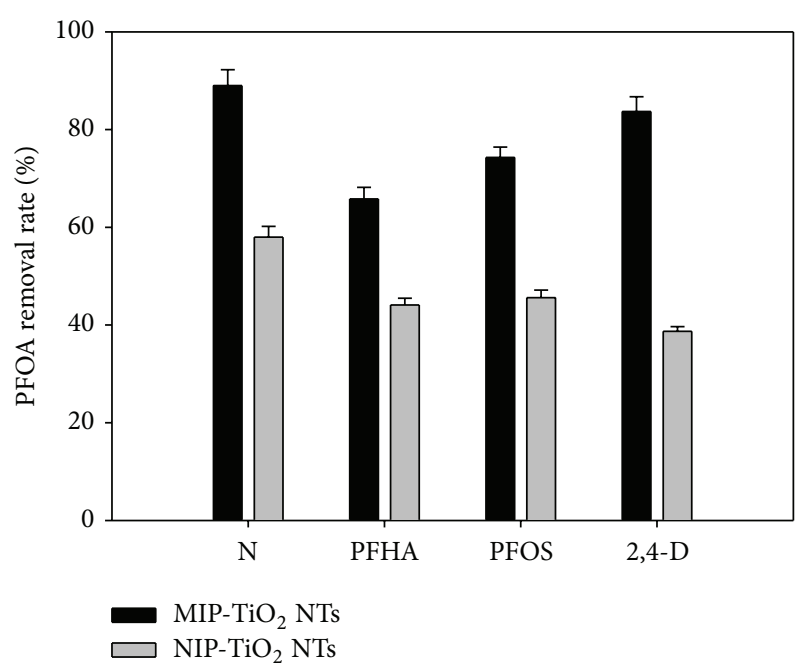

FIgUre 8: Decomposition selectivity of PFOA towards $\mathrm{MIP}^{-T i O}$ NTs in dual-solute solution in the presence of competitive pollutants. "N" represents only PFOA in the reaction solution.

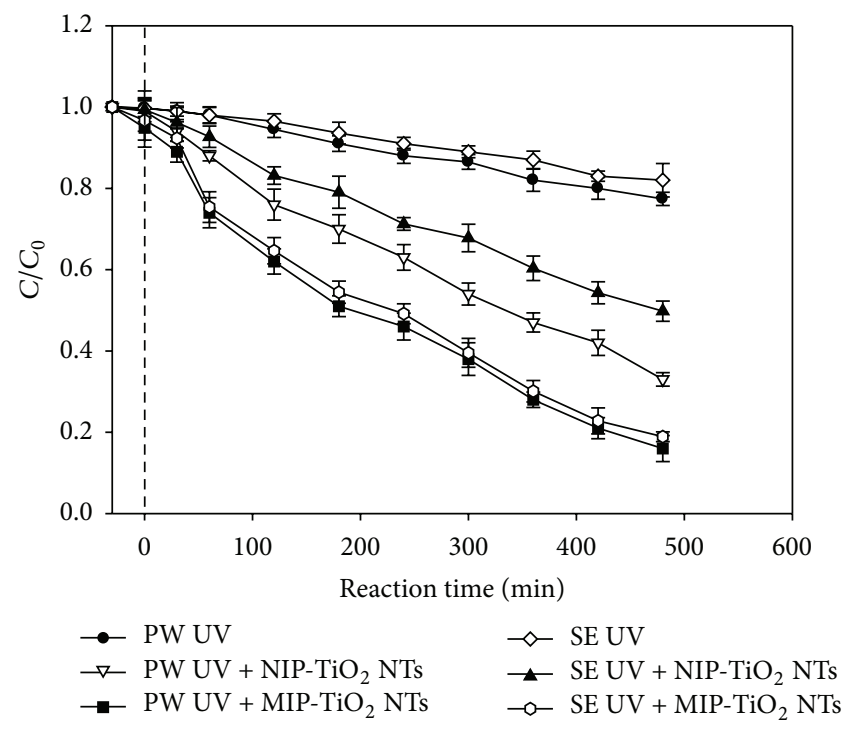

FIGURE 9: PFOA degradation in secondary effluent (SE) and pure water $(\mathrm{PW})$. PFOA concentration added in SE was the same as that in PW. Initial solution concentration $C_{0}$ and $\mathrm{pH}$ are $30 \mathrm{mg} / \mathrm{L}$ and 5, respectively.

Therefore, the difference in the photoreaction results can be explained by the fact that organic and inorganic matters were directly or indirectly responsible for the decreased PFOA degradation observed in the organic-rich (SE) water rather than acting as natural sensitizers for promotion of PFOA degradation $[26,27]$. For the NIP-TiO ${ }_{2}$ NTs, the superior degradation efficiency observed in pure water could be attributed to the lower amounts of organic and inorganic matters coexisting compared with those in the secondary effluent. Organic matter in the secondary effluent may have competed for adsorption sites on the surface of the NIP- $\mathrm{TiO}_{2}$ NTs and scavenge hydroxyl radicals [17,25]. Additionally, any inorganic salts present could also act as scavengers of hydroxyls and other oxidizing radical species and produce less reactive ion-radicals. However, anions have been reported to have little influence on the sorption of target PFCs by MIP or NIP-adsorbents at low salt concentrations [19].

Moreover, the MIP- $\mathrm{TiO}_{2}$ NTs exhibited significant photocatalytic activity in the secondary effluent, in which the PFOA removal efficiency was about the same as that in pure water owing to the considerable selectivity of the MIP-TiO ${ }_{2}$ NTs. Thus, water quality had little influence on PFOA degradation by the MIP-TiO 2 NTs. Footprint cavities generated on the surface of the $\mathrm{MIP}^{-\mathrm{TiO}_{2}}$ NTs may have inhibited the competitive adsorption between PFOA and organic matter. Furthermore, PFOA was preferentially adsorbed to the surface of $\mathrm{MIP}-\mathrm{TiO}_{2}$ NTs and was ionized to anionic PFOA $\left(\mathrm{C}_{7} \mathrm{~F}_{15} \mathrm{COO}^{-}\right)$because the initial $\mathrm{pH}$ of the solution was $5[9,24]$. Thus, to a certain extent, the negatively charged surface formed on the MIP$\mathrm{TiO}_{2}$ NTs would have produced a repulsion that decreased the scavenging of hydroxyl and other oxidizing radical species. It is deduced that this effect may be one of the main factors accounting for the observed difference in PFOA removal by the MIP-TiO ${ }_{2}$ NTs and NIP-TiO 2 NTs in secondary effluent. This reason may also explain the slight difference in PFOA removal observed in secondary effluent and pure water.

3.5. Effects of Scavengers. To clarify whether photogenerated oxidation species induced PFOA decomposition, the effects of chosen scavengers, namely, bulk water hydroxyl radicals (t-butanol), oxidant holes (2-propanol), electrons $\left(\mathrm{KBrO}_{3}\right)$, and superoxide radicals (p-benzoquinone), were investigated at $\mathrm{pH} 5$ in aerated solution [28-30].

As shown in Figure 10, the presence of t-butanol, 2propanol, and p-benzoquinone in reaction solution suppressed PFOA photocatalytic degradation. Among them, tbutanol and p-benzoquinone slightly inhibited photocatalysis, suggesting that hydroxyl radicals or superoxide radicals rarely participate in the photocatalytic degradation of PFOA. However, 2-propanol obviously restrained the oxidation of PFOA into short-chain perfluorinated compounds. The 2-propanol acted as a hole-scavenger to decrease the chance of reaction between hole and perfluoroalkyl anions $\left(\mathrm{C}_{7} \mathrm{~F}_{15} \mathrm{COO}^{-}\right)$. These results indicated that photogenerated holes are the main oxidant for PFOA decomposition, which also verifies why the MIP-TiO ${ }_{2}$ NTs were superior to the other catalysts in the degradation kinetics experiments. $\mathrm{KBrO}_{3}$ was found to enhance the PFOA oxidation process, partially owing to increased charge separation. This effect was caused by the acceptance of conduction band electrons by $\mathrm{KBrO}_{3}$ [29]:

$$
\mathrm{BrO}_{3}{ }^{-}+6 \mathrm{e}_{\mathrm{cb}}{ }^{-}+6 \mathrm{H}^{+} \longrightarrow \mathrm{Br}^{-}+3 \mathrm{H}_{2} \mathrm{O}
$$

Based on the present results and those reported in the literature $[6,9,10,24]$, PFOA degradation is mediated predominantly through the action of holes generated on the $\mathrm{TiO}_{2}$ surface. The proposed PFOA degradation mechanism is initiated by the excitation of $\mathrm{TiO}_{2}$ caused by UV irradiation; holes generated from excited $\mathrm{TiO}_{2}$ accept one electron from dissociated PFOA $\left(\mathrm{C}_{7} \mathrm{~F}_{15} \mathrm{COO}^{-}\right)$, generating PFOA radicals 


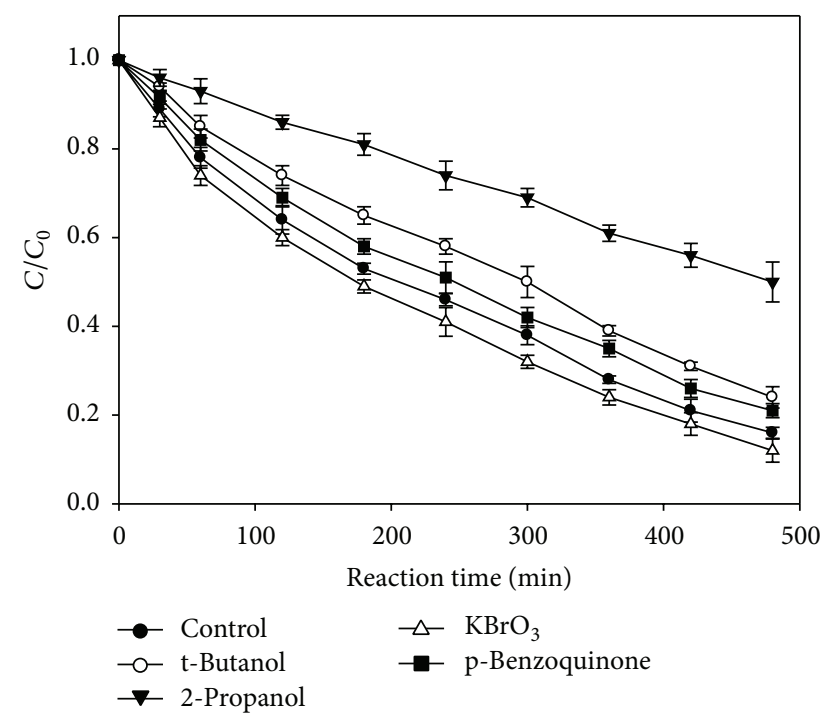

FIGURE 10: Effect of different scavengers on photocatalytic decomposition PFOA. The concentration of t-butanol, 2-propanol, $\mathrm{KBrO}_{3}$, p-benzoquinone in reaction solution were $0.1 \mathrm{mmol} / \mathrm{L}$.

$[6,9,10]$. PFOA exists as anionic compound when it enters the reaction solution [24] and is absorbed on the $\mathrm{MIP}-\mathrm{TiO}_{2}$ surface. This part of PFOA $\left(\mathrm{C}_{7} \mathrm{H}_{15} \mathrm{COO}^{-}\right)$reacts with valence band holes $\left(\mathrm{h}^{+}\right)$to form perfluoroperoxy radicals (6), which is confirmed by various studies in which the start of PFOA decomposition was reported to depend on the carboxylic functional group:

$$
\begin{aligned}
\mathrm{C}_{7} \mathrm{H}_{15} \mathrm{COOH} & \longrightarrow \mathrm{C}_{7} \mathrm{H}_{15} \mathrm{COO}^{-}+\mathrm{H}^{+} \\
\mathrm{C}_{7} \mathrm{H}_{15} \mathrm{COO}^{-}+\mathrm{TiO}_{2}-\mathrm{h}_{\mathrm{vb}}{ }^{+} & \longrightarrow \mathrm{TiO}_{2}-\mathrm{C}_{7} \mathrm{H}_{15} \mathrm{COO}
\end{aligned}
$$

The $\mathrm{C}_{7} \mathrm{H}_{15} \mathrm{COO}^{\circ}$ radicals are highly unstable and thus spontaneously undergo Kolbe decarboxylation to form $\mathrm{C}_{7} \mathrm{H}_{15} \cdot$ radicals via $(7)[6,9,24]$. The formed $\mathrm{C}_{7} \mathrm{~F}_{15} \cdot$ might subsequently react with water and electrons $\left(\mathrm{e}_{\mathrm{cb}}\right)$ on the $\mathrm{TiO}_{2}$ surface and further undergo $\mathrm{H}^{+}$and $\mathrm{F}^{-}$elimination to form $\mathrm{C}_{6} \mathrm{~F}_{13} \mathrm{COF}$. After hydrolysis, $\mathrm{C}_{6} \mathrm{~F}_{13} \mathrm{COF}$ is converted to $\mathrm{C}_{6} \mathrm{~F}_{13} \mathrm{COOH}$ with removal of $\mathrm{CF}_{2}$ units. Similarly, shorterchain $\mathrm{C}_{n-1} \mathrm{~F}_{2 n-1} \mathrm{COOH}$ forms stepwise over time accompanied by the loss of a $\mathrm{CF}_{2}$ unit:

$$
\begin{aligned}
& \mathrm{C}_{7} \mathrm{H}_{15} \mathrm{COO}^{\bullet} \longrightarrow \mathrm{C}_{7} \mathrm{H}_{15} \cdot \mathrm{CO}_{2} \uparrow \\
& \mathrm{C}_{7} \mathrm{H}_{15} \cdot+\mathrm{H}_{2} \mathrm{O} \stackrel{\mathrm{e}_{\mathrm{cb}}}{\longrightarrow} \mathrm{C}_{7} \mathrm{H}_{15} \mathrm{OH}+\mathrm{H}^{+} \\
& \mathrm{C}_{7} \mathrm{H}_{15} \mathrm{OH} \longrightarrow \mathrm{C}_{6} \mathrm{~F}_{13} \mathrm{COF}+\mathrm{HF} \\
& \mathrm{C}_{6} \mathrm{~F}_{13} \mathrm{COF}+\mathrm{H}_{2} \mathrm{O} \longrightarrow \mathrm{C}_{6} \mathrm{~F}_{13} \mathrm{COOH}+\mathrm{HF}
\end{aligned}
$$

\section{Conclusions}

Molecularly imprinted polymer-modified $\mathrm{TiO}_{2}$ nanotubes were synthesized. The molecular-imprinted polymer provided the $\mathrm{TiO}_{2}$ NTs with enhanced adsorption and selective photocatalytic activity toward PFOA. Our results indicate that these enhanced properties should mainly be attributed to footprint cavities and hydrogen bonding on the surface of the catalyst. Furthermore, the negative charge formed on the MIP-TiO ${ }_{2}$ NTs surface retarded charge recombination to further accelerate PFOA decomposition. The modified $\mathrm{TiO}_{2}$ NTs had outstanding selectivity for the target compound PFOA and anti-interference properties toward other substances in secondary effluent. The effects of chosen scavengers on reactive oxygen species clarified that the PFOA degradation behavior of the present catalysts is mediated predominantly through the action of generated holes on the $\mathrm{TiO}_{2}$ surface. The proposed PFOA degradation mechanism was given. Photocatalytic oxidation using $\mathrm{MIP}-\mathrm{TiO}_{2}$ NTs is expected to be a promising approach for effectively eliminating PFCs from water.

\section{Conflict of Interests}

The authors declare that there is no conflict of interests regarding the publication of this paper.

\section{Acknowledgments}

The study was financially supported by the National Natural Science Foundation of China (nos. 51322901 and 51479066), Foundation for Innovative Research Groups of the National Natural Science Foundation of China (51421006), a Project Funded by the Priority Academic Program Development of Jiangsu Higher Education Institutions, Foundation of Jiangsu Province Key Laboratory of Environmental Engineering (ZX2014003), and the Major Science and Technology Program for Water Pollution Control and Treatment (2012ZX07506-002).

\section{References}

[1] J. P. Giesy and K. Kannan, "Perfluorochemical surfactants in the environment," Environmental Science and Technology, vol. 36, no. 7, pp. 146A-152A, 2002.

[2] Z. W. Du, S. B. Deng, Y. Bei et al., "Adsorption behavior and mechanism of perfluorinated compounds on various adsorbents-a review," Journal of Hazardous Materials, vol. 274, pp. 443-454, 2014.

[3] H. W. Sun, F. S. Li, T. Zhang et al., "Perfluorinated compounds in surface waters and WWTPs in Shenyang, China: mass flows and source analysis," Water Research, vol. 45, no. 15, pp. 44834490, 2011.

[4] S.-K. Kim, J.-K. Im, Y.-M. Kang, S.-Y. Jung, Y. L. Kho, and K.-D. Zoh, "Wastewater treatment plants (WWTPs)-derived national discharge loads of perfluorinated compounds (PFCs)," Journal of Hazardous Materials, vol. 201-202, pp. 82-91, 2012.

[5] F. S. Li, H. W. Sun, Z. N. Hao et al., "Perfluorinated compounds in Haihe River and Dagu Drainage Canal in Tianjin, China," Chemosphere, vol. 84, no. 2, pp. 265-271, 2011.

[6] M. Sansotera, F. Persico, C. Pirola, W. Navarrini, A. Di Michele, and C. L. Bianchi, "Decomposition of perfluorooctanoic acid photocatalyzed by titanium dioxide: chemical modification of the catalyst surface induced by fluoride ions," Applied Catalysis B: Environmental, vol. 148-149, pp. 29-35, 2014. 
[7] Z. Song, H. Q. Tang, N. Wang, and L. H. Zhu, "Reductive defluorination of perfluorooctanoic acid by hydrated electrons in a sulfite-mediated UV photochemical system," Journal of Hazardous Materials, vol. 262, pp. 332-338, 2013.

[8] S. Gatto, M. Sansotera, F. Persico et al., "Surface fluorination on $\mathrm{TiO}_{2}$ catalyst induced by photodegradation of perfluorooctanoic acid," Catalysis Today, vol. 241, pp. 8-14, 2015.

[9] S. C. Panchangam, A. Y.-C. Lin, K. L. Shaik, and C.-F. Lin, "Decomposition of perfluorocarboxylic acids (PFCAs) by heterogeneous photocatalysis in acidic aqueous medium," Chemosphere, vol. 77, no. 2, pp. 242-248, 2009.

[10] Y.-C. Chen, S.-L. Lo, and J. Kuo, "Effects of titanate nanotubes synthesized by a microwave hydrothermal method on photocatalytic decomposition of perfluorooctanoic acid," Water Research, vol. 45, no. 14, pp. 4131-4140, 2011.

[11] T. Ochiai, Y. Iizuka, K. Nakata et al., "Efficient decomposition of perfluorocarboxylic acids in aqueous suspensions of $\mathrm{a} \mathrm{TiO}_{2}$ photocatalyst with medium-pressure ultraviolet lamp irradiation under atmospheric pressure," Industrial \& Engineering Chemistry Research, vol. 50, no. 19, pp. 10943-10947, 2011.

[12] C. Song, P. Chen, C. Y. Wang, and L. Y. Zhu, "Photodegradation of perfluorooctanoic acid by synthesized $\mathrm{TiO}_{2}-\mathrm{MWCNT}$ composites under $365 \mathrm{~nm}$ UV irradiation," Chemosphere, vol. 86, no. 8, pp. 853-859, 2012.

[13] X. Y. Li, P. Y. Zhang, L. Jin, T. Shao, Z. M. Li, and J. J. Cao, "Efficient photocatalytic decomposition of perfluorooctanoic acid by indium oxide and its mechanism," Environmental Science and Technology, vol. 46, no. 10, pp. 5528-5534, 2012.

[14] M. Takayose, K. Nishimoto, and J. Matsui, "A fluorous synthetic receptor that recognizes perfluorooctanoic acid (PFOA) via fluorous interaction obtained by molecular imprinting," Analyst, vol. 137, no. 12, pp. 2762-2765, 2012.

[15] W. L. Zhang, Y. Li, Q. Wang, C. Wang, P. Wang, and K. Mao, "Performance evaluation and application of surface-molecularimprinted polymer-modified $\mathrm{TiO}_{2}$ nanotubes for the removal of estrogenic chemicals from secondary effluents," Environmental Science and Pollution Research, vol. 20, no. 3, pp. 1431-1440, 2013.

[16] T. T. Tran, J. Z. Li, H. Feng et al., "Molecularly imprinted polymer modified $\mathrm{TiO}_{2}$ nanotube arrays for photoelectrochemical determination of perfluorooctane sulfonate (PFOS)," Sensors and Actuators B: Chemical, vol. 190, pp. 745-751, 2014.

[17] K. Mao, Y. Li, H. H. Zhang, W. L. Zhang, and W. M. Yan, "Photocatalytic degradation of $17 \alpha$-ethinylestradiol and inactivation of Escherichia coli using Ag-modified $\mathrm{TiO}_{2}$ nanotube arrays," CLEAN-Soil, Air, Water, vol. 41, no. 5, pp. 455-462, 2013.

[18] E. I. Seck, J. M. Doña-Rodríguez, C. Fernández-Rodríguez, O. M. González-Díaz, J. Araña, and J. Pérez-Peña, "Photocatalytic removal of 2,4-dichlorophenoxyacetic acid by using sol-gel synthesized nanocrystalline and commercial $\mathrm{TiO}_{2}$ : operational parameters optimization and toxicity studies," Applied Catalysis B: Environmental, vol. 125, pp. 28-34, 2012.

[19] Q. Yu, S. B. Deng, and G. Yu, "Selective removal of perfluorooctane sulfonate from aqueous solution using chitosan-based molecularly imprinted polymer adsorbents," Water Research, vol. 42, no. 12, pp. 3089-3097, 2008.

[20] M. H. Cao, B. B. Wang, H. S. Yu, L. L. Wang, S. H. Yuan, and J. Chen, "Photochemical decomposition of perfluorooctanoic acid in aqueous periodate with VUV and UV light irradiation," Journal of Hazardous Materials, vol. 179, no. 1-3, pp. 1143-1146, 2010.

[21] C. X. Huang, Z. K. Tu, and X. T. Shen, "Molecularly imprinted photocatalyst with a structural analogue of template and its application," Journal of Hazardous Materials, vol. 248-249, no. 1, pp. 379-386, 2013.

[22] X. B. Luo, F. Deng, L. J. Min et al., "Facile one-step synthesis of inorganic-framework molecularly imprinted $\mathrm{TiO}_{2} / \mathrm{WO}_{3}$ nanocomposite and its molecular recognitive photocatalytic degradation of target contaminant," Environmental Science and Technology, vol. 47, no. 13, pp. 7404-7412, 2013.

[23] F. Deng, Y. Liu, X. B. Luo et al., "Sol-hydrothermal synthesis of inorganic-framework molecularly imprinted $\mathrm{TiO}_{2} / \mathrm{SiO}_{2}$ nanocomposite and its preferential photocatalytic degradation towards target contaminant," Journal of Hazardous Materials, vol. 278, pp. 108-115, 2014.

[24] M.-J. Chen, S.-L. Lo, Y.-C. Lee, and C.-C. Huang, "Photocatalytic decomposition of perfluorooctanoic acid by transitionmetal modified titanium dioxide," Journal of Hazardous Materials, vol. 288, pp. 168-175, 2015.

[25] W. Zhang, Y. Li, Y. Su, K. Mao, and Q. Wang, "Effect of water composition on $\mathrm{TiO}_{2}$ photocatalytic removal of endocrine disrupting compounds (EDCs) and estrogenic activity from secondary effluent," Journal of Hazardous Materials, vol. 215216, pp. 252-258, 2012.

[26] R. R. Giri, H. Ozaki, T. Okada, S. Taniguchi, and R. Takanami, "Factors influencing UV photodecomposition of perfluorooctanoic acid in water," Chemical Engineering Journal, vol. 180, pp. 197-203, 2012.

[27] S. Vaalgamaa, A. V. Vähätalo, N. Perkola, and S. Huhtala, "Photochemical reactivity of perfluorooctanoic acid (PFOA) in conditions representing surface water," Science of the Total Environment, vol. 409, no. 16, pp. 3043-3048, 2011.

[28] A. Syoufian and K. Nakashima, "Degradation of methylene blue in aqueous dispersion of hollow titania photocatalyst: study of reaction enhancement by various electron scavengers," Journal of Colloid and Interface Science, vol. 317, no. 2, pp. 507-512, 2008.

[29] L. Ravichandran, K. Selvam, B. Krishnakumar, and M. Swaminathan, "Photovalorisation of pentafluorobenzoic acid with platinum doped $\mathrm{TiO}_{2}$," Journal of Hazardous Materials, vol. 167, no. 1-3, pp. 763-769, 2009.

[30] E. M. Rodríguez, G. Márquez, M. Tena, P. M. Álvarez, and F. J. Beltrán, "Determination of main species involved in the first steps of $\mathrm{TiO}_{2}$ photocatalytic degradation of organics with the use of scavengers: the case of ofloxacin," Applied Catalysis B: Environmental, vol. 178, pp. 44-53, 2015. 

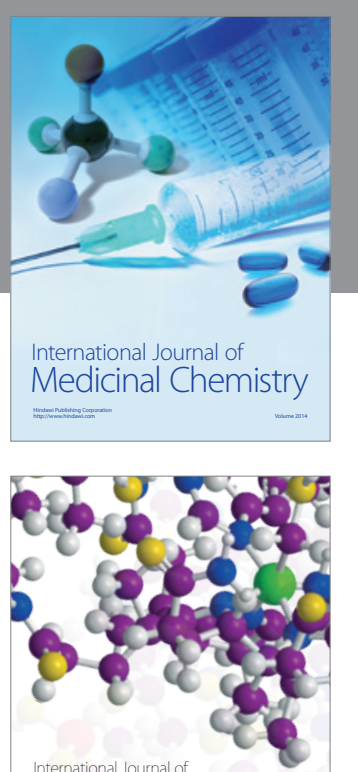

Carbohydrate Chemistry

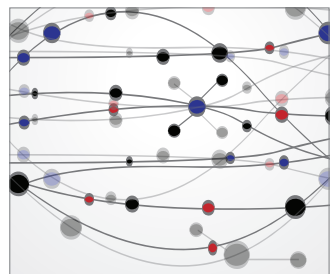

The Scientific World Journal
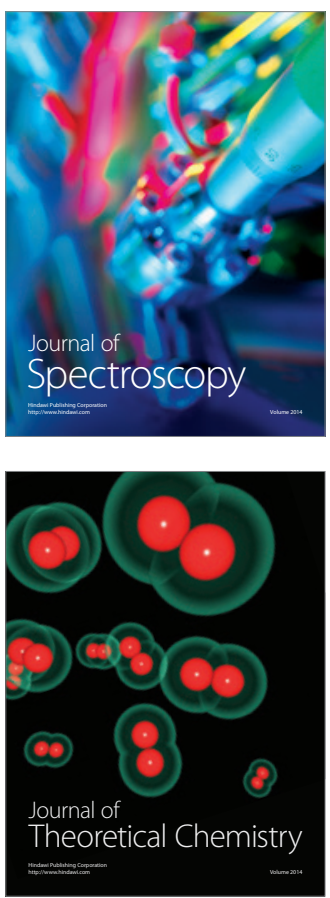
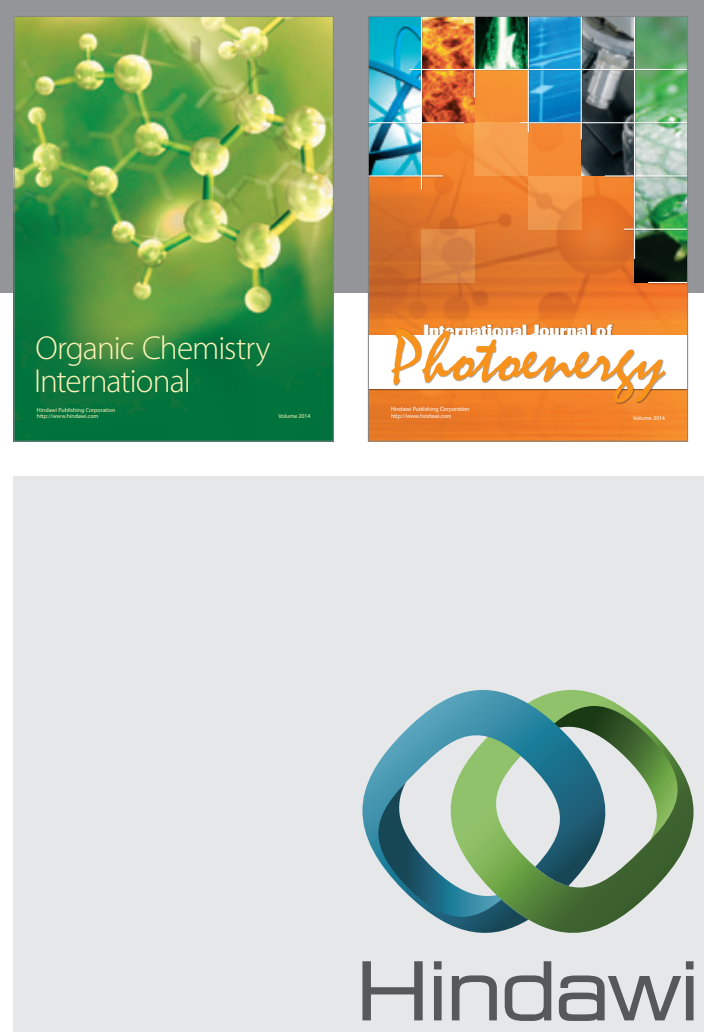

Submit your manuscripts at

http://www.hindawi.com

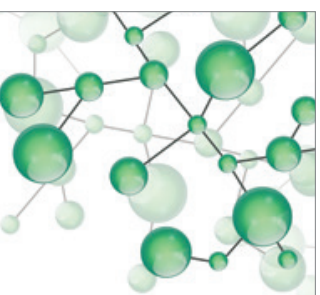

International Journal of

Inorganic Chemistry

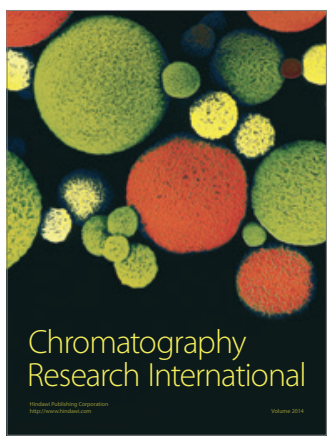

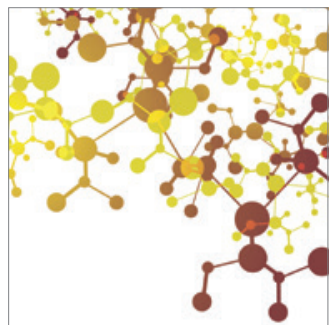

Applied Chemistry
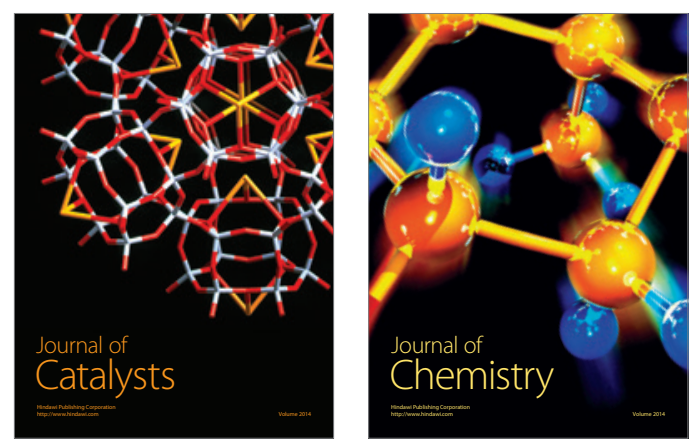
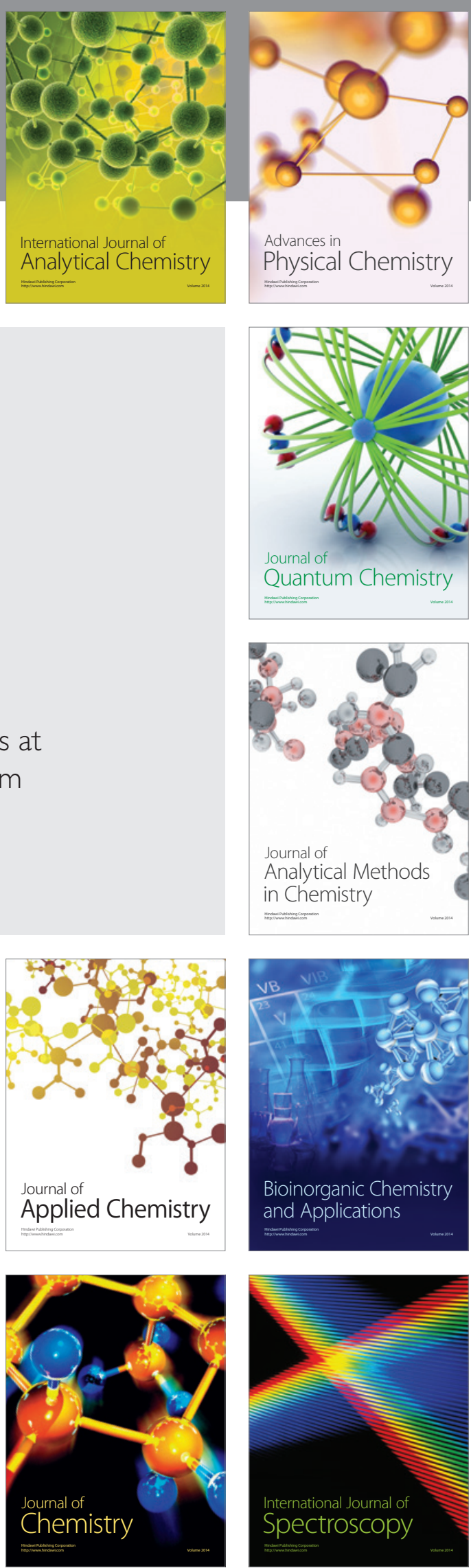